\title{
Hair Cosmetics for the Hair Loss Patient
}

\author{
Maria Fernanda Reis Gavazzoni Dias ${ }^{1} \quad$ Aline Falci Loures $^{2} \quad$ Chloe Ekelem $^{3}$
}

${ }^{1}$ Department of Dermatology, Antonio Pedro University Hospital, Federal Fluminense University, Niteroi, Brazil

2 Fundacao Lusiada, Santos, Brazil

3 Department of Dermatology, University of Utah, Salt Lake City, Utah, United States

Indian J Plast Surg 2021;54:507-513.
Address for correspondence Maria Fernanda Reis Gavazzoni Dias, MD, MSc, PhD, Department of Dermatology, Antonio Pedro University Hospital, Federal Fluminense University, Niteroi, Brazil

(e-mail: mgavazzoni@gmail.com).

\begin{abstract}
Keywords

- hair care

- hair cosmetics

- shampoo

- conditioner

- hair dyes

- hair straightening

- hair transplant

Medical professionals that treat patients with alopecia usually lack knowledge about hair cosmetics. Trichologists focus on hair cycling and growth problems and not on the hair shaft integrity. This may lead to abandon of the use of the prescribed treatment, such as topical minoxidil or to inadequate traumatic grooming habits that may jeopardize hair follicle health. Shampoos, hair dyes, and hair-straightening products may alter hair fiber structure, remove lipids, and elude protein. Hair procedures such as hair dying and straightening have side effects and health concerns, especially for pregnant women or sensitive hair and scalp patients. Hair breakage, follicle traction, frizz, contact dermatitis, and mutagenicity are possible side effects of hair cosmetics misuse. The proper use of hair care products may help to increase patients' adherence to alopecia treatments and avoid health problems related to inadequate application of hair cosmetics and procedures.
\end{abstract}

\section{Introduction}

Hair loss is a complex problem that causes great concern and emotional distress. The incorrect use of topical hair loss treatments may contribute to color fading and poor hair manageability that may lead to patients' dissatisfaction and loss to follow-up. Appropriate education about the correct use of hair care products and grooming is essential to help patients' adhere to alopecia treatment and posttransplantation hair care recommendations. This article aims to provide an overview of hair cosmetics to equip medical professionals better to advise alopecia patients on achieving the best possible hair and scalp health.

\section{Hair Structure}

\section{The Cuticle}

Hair fibers contain a thick protective, chemically resistant cover called a cuticle. It consists of flat overlapping scale-like structures that surround the central fiber core with the function of protecting the cortex from external environmental damage. The human cuticle is around 6 to 8 layers thick and consists of keratin protein, structural lipids, and high sulfur keratin-associated proteins (KAP). ${ }^{1}$ Caucasians and Asians have more layers than individuals of African descent. ${ }^{2}$

The 18-methyl eicosanoic (18-MEA) acid is located at the cuticle-cuticle cell (CMC), attached to ultrahigh sulfur protein. The 18-MEA is responsible for hair hydrophobicity which is important to hair manageability, integrity, and protein protection. ${ }^{3}$ The loss of 18-MEA caused by alkaline chemical treatments, such as dying and hair straightening is the most common cause of hair damage. ${ }^{3-5}$

\section{The Cortex}

The cortex accounts for the majority of the hair fiber mass (75\%) and plays a significant role in determining intrinsic published online

December 27, 2021
DOI https://doi.org/ 10.1055/s-0041-1739241. ISSN 0970-0358.

\footnotetext{
(c) 2021. Association of Plastic Surgeons of India. All rights reserved. This is an open access article published by Thieme under the terms of the Creative Commons Attribution-NonDerivative-NonCommercial-License, permitting copying and reproduction so long as the original work is given appropriate credit. Contents may not be used for commercial purposes, or adapted, remixed, transformed or built upon. (https://creativecommons.org/ licenses/by-nc-nd/4.0/)

Thieme Medical and Scientific Publishers Pvt. Ltd., A-12, 2nd Floor, Sector 2, Noida-201301 UP, India
} 
Table 1 Classification of surfactant and hair types

\begin{tabular}{|c|c|c|c|}
\hline \multicolumn{4}{|c|}{ Classification of the surfactants } \\
\hline Charge & Ingredients & Product type & Hair type \\
\hline Anionic & $\begin{array}{l}\text { Ammonium lauryl sulfate, sodium laureth } \\
\text { sulfate, sodium lauryl sarcosinate, sodium } \\
\text { myreth sulfate, sodium pareth sulfate, } \\
\text { sodium stearte, sodium lauryl sulfate, } \alpha \text {-olefin } \\
\text { sulfonate, ammonium laureth sulfate }\end{array}$ & $\begin{array}{l}\text { Sulfate shampoo and } \\
\text { clarifying shampoo }\end{array}$ & Oily hair, Asian hair \\
\hline Cationic & $\begin{array}{l}\text { Trimethylalkylammonium chlorides and the } \\
\text { chlorides or bromides of benzalkonium and } \\
\text { alkylpyridinium ions }\end{array}$ & $\begin{array}{l}\text { Used in combination with } \\
\text { other surfactants as an } \\
\text { antistatic agent }\end{array}$ & All types of hair \\
\hline Nonionic & $\begin{array}{l}\text { Fatty alcohols, cetyl alcohol, stearyl alcohol, } \\
\text { cetostearyl alcohol, and oleyl alcohol }\end{array}$ & Cowash & $\begin{array}{l}\text { African hair; severely } \\
\text { damaged hair }\end{array}$ \\
\hline Amphotheric & $\begin{array}{l}\text { Alkyl iminopropionates and (amido) betaines } \\
\text { and cocobetaine }\end{array}$ & Sulfate-free shampoo & $\begin{array}{l}\text { Chemical treated hair; } \\
\text { infants }\end{array}$ \\
\hline
\end{tabular}

strength. There is less cysteine in the cortex than in the cuticle. The $\alpha$-helix is held coiled by chemical forces such as ionic forces, hydrogen bonds, Van der Waal forces, and disulfide bonds. The helical structure is responsible for elasticity and hair strength. ${ }^{6-8}$

\section{Hair Care and Products}

\section{Shampoos}

Shampoos are products that primarily aim to clean the scalp. Shampoos are often composed of 10 to 30 ingredients, including cleansing agents, also known as surfactants (-Table 1), conditioning agents, $\mathrm{pH}$ adjusters, fragrances, and other additives. ${ }^{9-12}$

Sulfate free, cowash, and no poo are recently introduced concepts of hair washing, targeting sensitive hair regimens as well as hair of African descent. ${ }^{2}$

Cowashing refers to washing the hair with a nonionic surfactant. It is thought to gently cleanse the hair and scalp while maintaining moisture. ${ }^{11}$ Sulfate-free (low-poo) and cowash products prevent the excessive removal of the natural lubrication of the hair shaft and excess water loss, but they do so via different mechanisms. ${ }^{13}$ While the cowash uses nonionic surfactants, such as cetyl alcohol, low poo is the same as sulfate-free shampoo and uses amphoteric surfactants such as cocobetaine or quaternary ammonium salts. ${ }^{14}$ An exclusively cowashing routine needs a clarifying (sulfate) shampoo every 15 days to avoid buildup.

The "no poo" technique refers to washing the hair with baking soda, apple vinegar, or just water. ${ }^{14,15}$ This technique does not provide a proper cleansing of the scalp and there are currently no reports of its efficacy.

Extremely damaged hair or sensitive, dry post-hair-implantation scalp may also benefit from the hair routine previously detailed, especially the sulfate-free shampoos ( - Fig. 1 ).

\section{Antidandruff Shampoos}

Alopecia conditions may be associated with scalp bacterial and fungal dysbiosis and a medicated shampoo with keto-

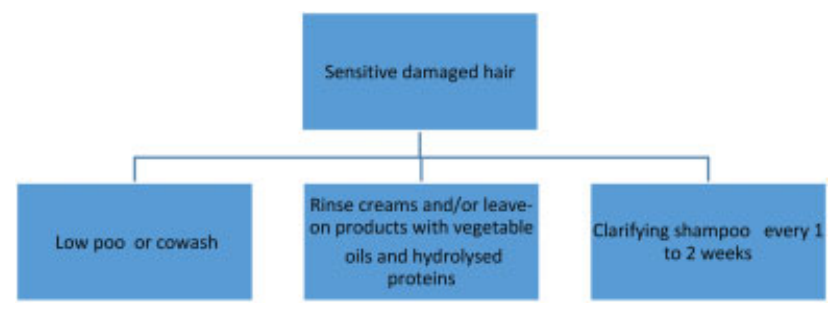

Fig. 1 Recommended routine for damaged hair or sensitive scalp.

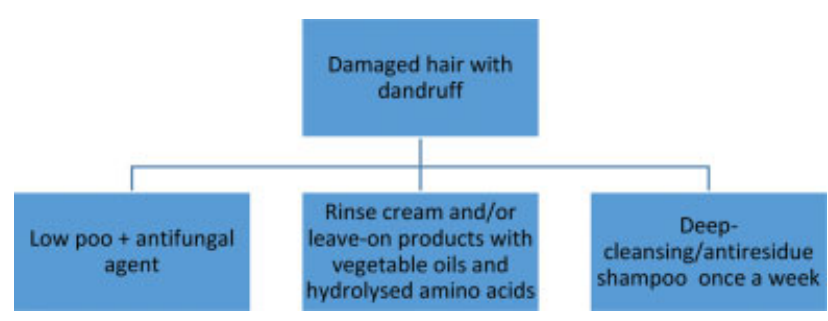

Fig. 2 Suggested hair care regimen for sensitive hair with and without dandruff.

conazole, salicylic acid, climbazole, or coaltar may help to maintain a healthy scalp microbiome $e^{9,16,17}$ and treat seborrheic dermatitis. ${ }^{10}$ As most dermatologist-prescribed shampoos have a pH higher than baseline scalp (5.5) and hair shaft $\mathrm{pH}$ (3.67), ${ }^{18}$ patients commonly complain of hair stiffening or drying when using them. If the prescription of an alkaline shampoo is necessary, the application of a low $\mathrm{pH}$ conditioner after shampooing may restore the net electrical charge and minimize frizz, stiffness, and dullness ${ }^{18}$ (-Fig. 2).

\section{Conditioning Agents}

The application of hair conditioners aims to reduce hair weathering and damage by lowering interfiber friction, reducing combing forces, neutralizing the negative charge of the hair fiber, and restoring hydrophobicity. Examples of conditioning agents include polymers, oils, hydrolyzed amino acids, and cationic molecules ${ }^{6,19-21}$ (- Fig. 3 ). 


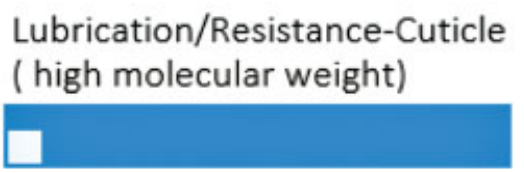

silicone/polymers

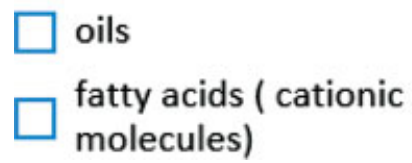

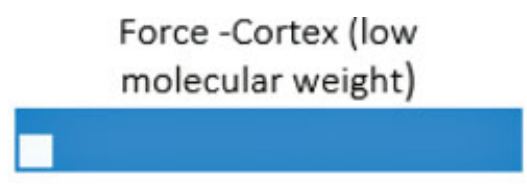

hydrolyzed amino acids

polymers

fatty acids
Anti-static

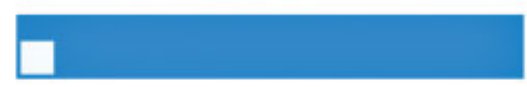

polymers

hydrolyzed amino acids (+)

Fig. 3 The main groups of conditioning agents and their site of action, according to the molecular weight.

\section{Hydrolyzed Proteins}

Hydrolyzed amino acids are protein-derived substances that result in temporary increase in hair strength and hydrophobicity. ${ }^{6,9,22-24}$ Hydrolyzed amino acids are derived from animal or vegetable sources and are efficient hair restorers and natural moisturizers.

Protein hydrolysates consist of positively charged amino acids with low molecular weight, usually under 1,000 Da. These proteins are capable of reaching the deep cortex, neutralizing the negatively charged net on the entire fiber, and promoting surface coating. ${ }^{25,26}$ The incorporation of hydrolyzed amino acids is more efficient with heat, leading to a more stable and complete deposition at the cuticle cell membrane complex. ${ }^{23}$

\section{Oils}

Vegetable oils have long been used to improve hair lubrication and manageability. ${ }^{6,27}$ A recent study investigating the effect of mineral oil, sunflower oil, and coconut oil on preventing hair damage concluded that coconut oil was the only oil that reduced protein loss for both damaged and undamaged hair, when used as a pre- and postwash agent. Coconut oil contains lauric acid, which has a high affinity for hair proteins, and a low molecular weight, allowing the oil to penetrate to the cortex. ${ }^{28,29}$ Another common oil in hair formulations is castor oil that is extracted from the seeds of the Ricinus communis plant. The oil is rich in ricinolein, a monounsaturated fatty acid that allows it to act as moisturizer. Argan oil has a high tocopherol and polyphenol content as well as a high antioxidant capacity; however, its use as Moroccan oil for hair conditioning lacks scientific data. 6,30 Silicone-free products use vegetable oils instead of silicones, with a minor hair smoothing effect.

The application of virgin oil directly to hair requires caution as it may trigger a hair matting condition of unknown mechanism known as plica polonica. 31,32

\section{Silicones}

Silicones are heat-resistant hybrid polymers derived from silicon dioxide present in beach sand. ${ }^{6}$ Silicones are used in shampoos and conditioners and they differ on deposition and solubility in water. ${ }^{19}$ These compounds can increase hair body, protect the hair shaft from chemical and environmental damage, and improve hair hydrophobicity and shine.
Some silicones have positively charged polar sites to better attach to the negatively charged hair surface and enhance deposition on chemically treated hair. ${ }^{33}$

Water-insoluble silicones cannot be combined with cowash products due to their great deposition under the scales, resulting in accumulation of residues that impair hair manageability ${ }^{11}$

Silicone oils protect the hair by coating the shaft with easily-to-spread thin films. Silicones are globally referred to as thermoactive heat protectors and there is scientific evidence to confirm this statement. ${ }^{34}$

\section{Deep Conditioners and Leave-on Products}

Protein hydrolysates, silicones, vegetable oils, and cationic surfactants are frequently found in deep conditioners and leave-on products. Deep conditioners are usually left on the hair for at least 10 minutes and may include the additional application of heat with a hairdryer or hot towel. ${ }^{35}$ The added heat helps to lift cuticle scales and causes swelling of the hair shaft, allowing deeper penetration of conditioning agents $s^{9,34,36-38}$

\section{Hair Cosmetics and Topical Minoxidil}

Though hair stiffness is a common complaint among patients using topical minoxidil, data about minimizing this cosmetic effect are lacking. The stiffening is possibly due to extraction of cuticle free lipids by the alcohol in minoxidil or by the deposition of the formula components themselves under the cuticle scales.

In this author's experience, the application of leave-on products rich in vegetable oils and/or soluble silicones directly to the hair fiber surface prior to the use of topical minoxidil may provide a physical barrier that prevents the absorption of the topical agents by the fiber. The combination of both products can be easily shampooed off each morning. The combination of topical minoxidil with cowash and dry shampoos may increase residue deposition.

Oral minoxidil is a possible substitute for topical minoxidil; however, additional studies are needed to ensure its benefit, safety, and efficacy. ${ }^{17,38}$

\section{Hair Dyes}

Many patients with alopecia have a desire to dye their hair. ${ }^{21}$ Hair dyes can be classified as temporary, semipermanent, demipermanent, or permanent. ${ }^{20}$ 
Temporary dyes are water-soluble high-molecular-weight products available as gels, mousses, and sprays that are easily removed by shampooing. Because they do not penetrate the cuticle layer they are safer for sensitive hair. ${ }^{20,37}$

Semipermanent dyes are low-molecular-weight products that do not require any oxidation for their coloring action. They last for around eight washes and are minimally damaging to the hair shaft. Of note, they can only darken the hair to up to 3 shades. ${ }^{20,37}$

Demipermanent hair dyes are similar to semipermanent dyes as they do not contain ammonia or ethanolamine, but have a low concentration of hydrogen peroxide (2\%). These products usually remain present for 10 to 12 shampoos. ${ }^{6}$

Permanent dyes are the most effective for coloring gray hair. ${ }^{37}$ Permanent dyes cannot be washed out by shampoos or topical minoxidil, but slowly fade from weather oxidation. The permanent dyeing is an oxidation reaction that allows the pigments to get inside the cortex and add color to each hair shaft. The oxidation reaction requires the combination of para dyes, including paraphenylenediamine (PPD), paratoluenediamine, and paraaminophenol, known as the primary intermediaries, with hydrogen peroxide. ${ }^{20}$ PPD is responsible for pale shades and aminophenol is responsible for dark shades.

To overcome the cuticle and reach the cortex, the product must have an alkaline pH able to open the scales. Most often, the permanent dyes use ammonia or ethanolamine to increase the $\mathrm{pH}$. Both substances remove the natural cuticle lipid, 18-metil eicosanoic acid, which confers hydrophobicity to the fiber. Therefore, although permanent dye provides a desired long-lasting effect, it also causes more hair damage compared with nonpermanent dyes. 6,37

\section{Hair Bleaching}

The primary purpose of bleaching human hair is to lighten the natural color of the hair. The bleaching process occurs in the $\mathrm{pH}$ range of 8 to 10 and needs ammonia or ethanolamine and hydrogen peroxide to occur. This process causes significant damage to hair.

The lighter the shade of hair, the higher the levels of ammonia and hydrogen peroxide needed. Bleaching is also required for permanent hair dyes, even when only small color increment changes are desired. The process of bleaching removes the 18-MEA and the hydrophobic surface barrier, lowering the isoelectric point of hair. Chemical bleaches weaken the cell membrane complex and oxidize cysteine residues, effectively dissolving proteins in regions rich in cysteine and leading to cuticle scale lifting as well as protein loss. $^{20,37}$

Patients with alopecia or sensitive hair should be counseled to avoid bleaching. ${ }^{17,22}$

\section{Hair Straightening}

The hair keratin molecule is held together by weak forces like hydrogen bonds, strong forces like disulfide bonds, and Van der Waals forces. ${ }^{35}$ Each cysteine amino acid is connected to another cysteine of the neighboring keratin molecule forming a disulfide bond (S-S) ${ }^{39}$ Ammonium thioglycolate can break disulfide bonds (S-S) of the cysteine amino acid in the keratin molecule, separating the two strands of keratin and weakening the hair. The hair is then rebounded to a straight shape by firmly pressing it with a flat-iron. To stop the reaction, a lotion containing hydrogen peroxide is added to the hair to reconstitute the S-S.

Hydroxide relaxers act differently, though also at the same $\mathrm{S}-\mathrm{S}$ of the cysteine residue. They break S-S by removing one atom of sulfur from the S-S, thereby converting it into a lanthionine bond in a process called lanthionization. ${ }^{6,39}$ Side effects of chemical relaxers are protein loss and decreased hydrophobicity ${ }^{6,40}$ (- Figs. 4 and $\mathbf{5}$ ).

Formaldehyde is a chemically organic product, most used in the cosmetic industry in a concentration of $0.2 \%$ as a preservative and $5 \%$ as a nail hardener with no hair smoothing effect. ${ }^{6,37}$ Although forbidden by global health agencies, application of high levels of formaldehyde is a popular hair smoothing procedure known as the Brazilian keratin treatment (BKT) ${ }^{41}$ In BKT products, the formaldehyde binds to the keratin molecule at the water-hydrogen-broken-bridge sites, promoting crosslinking of the molecules. The procedure provides smoothing of the cuticles, shine, and frizz control. It is distinct from the chemical relaxers discussed earlier and is compatible with highlighted hair. ${ }^{42}$ Newer products that contain formaldehyde releasers, such as methylene glycol and glyoxylic acid, are still not authorized by global health agencies. The formaldehyde releasers are activated by heat, usually from a flat iron, which causes dehydration of the molecule and formation of formaldehyde,

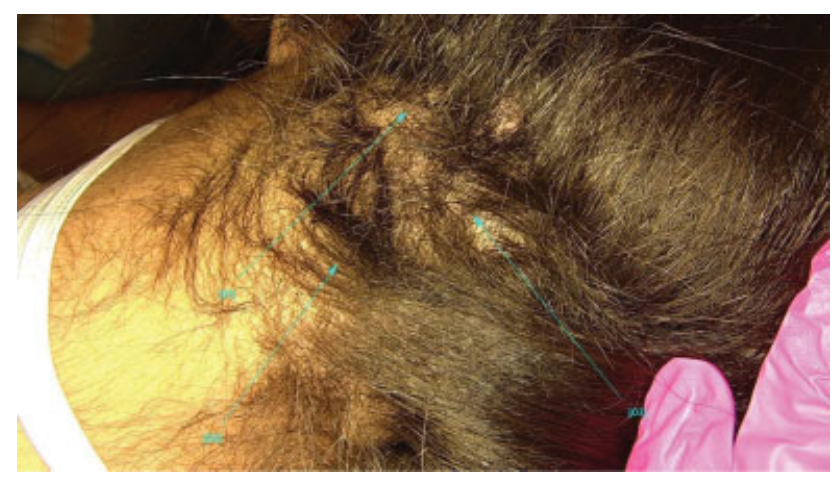

Fig. 4 Postthioglycolate hair loss.

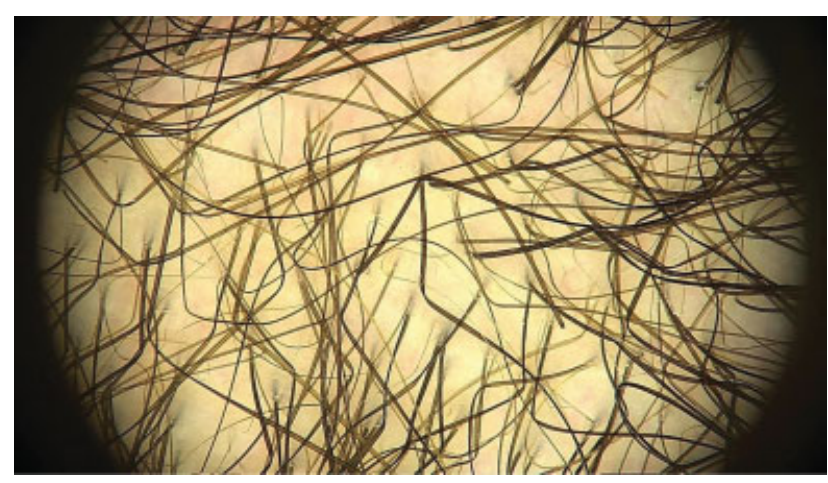

Fig. 5 Dermoscopy showing hair shaft flattening and twisting after the use of thioglacolate. The hair fiber is curved at a $90^{\circ}$ angle. 
glyoxylic acid, and glyoxiloyl carbocysteine. ${ }^{43}$ The flat iron is applied at a temperature of $230^{\circ} 15$ to 20 times on the same hair strand and may cause protein loss and hair degradation if the hair is already damaged. ${ }^{34}$

\section{Hair Cosmetic Adverse Reactions}

Lucca et $\mathrm{al}^{44}$ described that $27 \%$ of adverse reactions related to cosmetics are due specifically to hair cosmetics. Hair sprays and hair coloring products are associated with lung damage, while shampoos are related to hair frizz and dryness with no scalp symptoms reported. ${ }^{44}$ Malkani et al concluded that long-term use of hairstyling procedures is related to hair damage, but not to hair loss. ${ }^{44}$ Shetty at al reported that women who underwent repeated chemical hair relaxing were more prone to present with frizzy hair, dandruff, thinning and weakening of the hair, hair loss, greying of hair, and split ends. ${ }^{45}$

There is a concern regarding the relationship between the use of hair coloring and hair straightening and a higher risk of malignancy. ${ }^{14}$ Personal use of hair dyes was associated with a nonstatistically significant risk of leukemia. ${ }^{46}$ The authors found that increased risk was associated with the use of dark shade hair pigments for 15 years or more, as well as with cigarette smoking. ${ }^{41}$ Takkouche et al did not find any association between breast cancer and the use of hair dyes, but Gere et al reported an 18.8\% increased risk of future development of breast cancer among hair dye users. The authors suggest a maximum concentration of $2 \%$ of PPD, as recommended by the Scientific Committee on Consumer Safety of the European Commission. ${ }^{41,42}$ Contact dermatitis is another possible side effect of the hair dyes ${ }^{47}$ and PPD is the most common contact sensitizer. ${ }^{48,49}$ Alternative hair-dye products may contain paratoluenediamine sulfate (PTDS) as a PPD substitute (PPD-free products). Only around $57 \%$ of patients allergic to PPD are able to tolerate PTDS. ${ }^{50}$

Kraeling et al reported that lawsone could be absorbed through the skin with mutagenic concerns and should be avoided during pregnancy and lactation..$^{51}$

In 2010, aromatic amines and organic dyes were evaluated by the International Agency of Research on Cancer (IARC). They concluded that there is a higher carcinogenic risk to hairdressers, but not to personal users. ${ }^{52}$

Parabens, phthalates, and toluene are considered possible endocrine-disrupting chemicals associated with precocious puberty, higher risk of breast cancer, and obesity. Therefore, the use of hair dyes in children or pregnant women is not recommended. ${ }^{53}$

Cases of neonatal medulloblastoma and cardiac malformations were also associated with the use of maternal hair dyes. ${ }^{54-56}$ A Brazilian study, in 2013, associated the development of early-age leukemia to exposure to hair dyes and hairstraightening cosmetics by the pregnant women. ${ }^{57}$

Formaldehyde is a possible carcinogenic substance that can cause contact dermatitis, eye irritation, pain, tearing, blurred vision, and asphyxiation. ${ }^{34}$ Long-term inhalation can cause respiratory tract and central nervous system malignancies. ${ }^{6}$ Gavazzoni et al reported the development of eczema-like psoriasiform lesions, located on the scalp of BKT
Table 2 Recommended routine for post hair transplant

\begin{tabular}{l}
\hline Post hair transplant care \\
\hline - The use of sulfate-free shampoo is recommended. \\
- Avoid direct exposure of the scalp to pressurized water \\
and do gently apply shampoo and conditioner. \\
- Prefer nonpermanent hair dyes. \\
- Avoid BKT or hair-straightening procedure. \\
- Avoid hair bleaching. \\
- For sebderm (dandruff) treatment, use low-pH sulfate-free \\
shampoo associated with antifungal agent. \\
- Before applying topical minoxidil, protect the hair shaft \\
with leave-on product containing vegetable oils, soluble \\
- Silicones, and hydrolyzed amino acids. \\
- Use deep cleansing shampoo every 15 days. \\
- Virgin vegetable oils should not be applied directly to the \\
scalp. \\
- Hair dryers and hot iron should be avoided at the site of \\
the transplant or applied with caution.
\end{tabular}

users, suggesting a drug reaction phenomenon possibly from formaldehyde absorption. ${ }^{24}$

\section{Post-Hair Transplantation Recommendations}

After hair transplantation, it is essential to follow the surgeon's postoperative instructions to promote the fastest healing possible. Recommendations for washing the hair for the first time may vary from 2 to 4 days after surgery and may include instructions to avoid direct exposure of the scalp to pressurized water. Following hair transplantation, regular use of the proper shampoo may result in reduction of scabbing and erythema. After the swelling and redness of the acute postoperative phase have subsided, the patient should be prepared to initiate a new routine of hair care. During washing, the use of sulfate-free shampoos with caution is recommended. The frequency of shampooing can be daily or every other day, depending on scalp oil content and amount of sweating. Schweiger et al described and encourage the use of a mild surfactant shampooing regimen. ${ }^{26}$

Traction alopecia is a possible complication of a long-term use of inflammatory hair grooming habits such as braids, extensions, dreadlocks, ballerinas' buns, and religious practices, such as those in Sikhism. It is recommended that newly transplanted hair be handled with extreme care, avoiding traction and excess of rubbing while washing and combing (-Table 2).

\section{Conclusions}

Among the available hair relaxers, thioglycolate is the best option as it minimizes protein loss. Hairdryers and flat irons should be used with care as far as possible from the scalp skin. Hair stiffness caused by the use of topical lotions, such as minoxidil, can be mitigated if applied directly to the scalp and in combination with a leave-on product containing soluble silicones and vegetable oils. If the hair becomes dull with excessive residue, a clarifying shampoo should be used every 15 days. It is important that clinicians educate 
hair-transplant patients about the safe hair care routine that will follow the surgery. In the authors' experience, a safe routine consists of daily shampooing with sulfate-free products, followed by conditioning rinsing creams rich in hydrolyzed amino acids, vegetable oils, and water-soluble silicones. If dying the new hair is necessary, we recommend the use of nonpermanent dyes. Bleaching, hair relaxers, and BKT should be avoided. Traction grooming habits should be avoided at the site of the transplantation.

\section{Conflict of Interest}

None declared.

\section{References}

1 Velasco MVR, Dias TCdS, Freitas AZd, et al. Hair fiber characteristics and methods to evaluate hair physical and mechanical properties. Braz J Pharm Sci 2009;45(01):153-162

2 Ahn CS, Suchonwanit P, Foy CG, Smith P, McMichael AJ. Hair and scalp care in African American women who exercise. JAMA Dermatol 2016;152(05):579-580

3 Jones LN, Rivett DE. The role of 18-methyleicosanoic acid in the structure and formation of mammalian hair fibres. Micron 1997; 28(06):469-485

4 Takahashi T, Yoshida S. Distribution of glycolipid and unsaturated fatty acids in human hair. Lipids 2014;49(09):905-917

5 Robbins CR. Chemical and Physical Behavior of Human Hair. New York, NYSpringer; 2012

6 Gavazzoni Dias MF. Hair cosmetics: an overview. Int J Trichology 2015;7(01):2-15

7 Thibaut S, de Becker E, Bernard BA, et al. Chronological ageing of human hair keratin fibres. Int J Cosmet Sci 2010;32(06):422-434

8 Tanus A, Oliveira CC, Villarreal DJ, Sanchez FA, Dias MF. Black women's hair: the main scalp dermatoses and aesthetic practices in women of African ethnicity. An Bras Dermatol 2015;90(04):450-465

9 D'Souza P, Rathi SK. Shampoo and conditioners: what a dermatologist should know? Indian J Dermatol 2015;60(03):248-254

10 Trüeb RM. Shampoos: composition and clinical applications [in German]. Hautarzt 1998;49(12):895-901

11 Gavazzoni Dias MFR. Pro and contra of cleansing conditioners. Skin Appendage Disord 2019;5(03):131-134

12 Trüeb RM. Shampoos: ingredients, efficacy and adverse effects. J Dtsch Dermatol Ges 2007;5(05):356-365

13 Luz GFSd. Development of cosmetic formulations with vegetable oils for curly hair. 2018

14 Cline A, Uwakwe LN, McMichael AJ. No sulfates, no parabens, and the "no-poo" method: a new patient perspective on common shampoo ingredients. Cutis 2018;101(01):22-26

15 Bosley RE, Daveluy S. A primer to natural hair care practices in black patients. Cutis 2015;95(02):78-80,106

16 Saxena R, Mittal P, Clavaud C, et al. Comparison of healthy and dandruff scalp microbiome reveals the role of commensals in scalp health. Front Cell Infect Microbiol 2018;8:346

17 Sinclair R, Patel M, Dawson TL Jr, et al. Hair loss in women: medical and cosmetic approaches to increase scalp hair fullness. Br J Dermatol 2011;165(Suppl 3):12-18

18 Gavazzoni Dias MF, de Almeida AM, Cecato PM, Adriano AR, Pichler J. The shampoo pH can affect the hair: myth or reality? Int J Trichology 2014;6(03):95-99

19 Draelos ZK. Hair cosmetics. Dermatol Clin 1991;9(01):19-27

20 Madnani N, Khan K. Hair cosmetics. Indian J Dermatol Venereol Leprol 2013;79(05):654-667

21 Draelos ZD. Hair care and dyeing. Curr Probl Dermatol 2015; 47:121-127
22 Draelos ZD. Shampoos, conditioners, and camouflage techniques. Dermatol Clin 2013;31(01):173-178

23 Barba C, Méndez S, Roddick-Lanzilotta A, Kelly R, Parra JL, Coderch L. Cosmetic effectiveness of topically applied hydrolysed keratin peptides and lipids derived from wool. Skin Res Technol 2008;14 (02):243-248

24 Gavazzoni-Dias MF, Rochael M, Vilar E, Tanus A, Tosti A. Eczemalike psoriasiform skin reaction due to Brazilian keratin treatment. Skin Appendage Disord 2016;1(03):156-162

25 Roddick-Lanzilotta A, Kelly R, Scott S, Mitchell G, Chahal SP. Protecting the hair with natural keratin biopolymers. Cosmetics and Toiletries 2006;121(05):61-68

26 Monteiro VF, Natal AMD, Soledade LEB, Longo E. Morphological analysis of polymers on hair fibers by SEM and AFM. Mater Res 2003;6(04):501-506

27 Habe T, Tanji N, Inoue S, et al. ToF-SIMS characterization of the lipid layer on the hair surface. I: the damage caused by chemical treatments and UV radiation. Surf Interface Anal 2011;43(12):410-412

28 Rele AS, Mohile RB. Effect of mineral oil, sunflower oil, and coconut oil on prevention of hair damage. J Cosmet Sci 2003;54 (02):175-192

29 Rele AS, Mohile RB. Effect of coconut oil on prevention of hair damage. Part I. J. Cosmet. Sci 1999;50(06):327-339

30 López LC, Cabrera-Vique C, Venegas C, et al. Argan oil-contained antioxidants for human mitochondria. Nat Prod Commun 2013;8 (01):47-50

31 Maduri VR, Vedachalam A, Kiruthika S. "Castor Oil"-The culprit of acute hair felting. Int J Trichology 2017;9(03):116-118

32 Osório F, Tosti A. Hair weathering, part 2: clinical features, diagnosis, prevention, and treatment. Cosmetic Dermatology 2011;24(12):555-559

33 Villa ALV, Aragão MRS, Dos Santos EP, et al. Feather keratin hydrolysates obtained from microbial keratinases: effect on hair fiber. BMC Biotechnol 2013;13(01):15

34 Leonardo Spagnol Abraham LSA, Andreia Mateus Moreira AMM. Larissa Hanauer de Moura LHdM, Maria Fernanda Reis Gavazzoni MFRG, Flávia Alvim Sant'Anna Addor FASAA. Hair care: a medical overview (part 2). 2009;1(04):

35 Draelos ZD. Hair Care: An Illustrated Dermatologic Handbook. London, United KingdomCRC Press; 2004

36 Sinclair RD. Healthy hair: what is it? J Investig Dermatol Symp Proc 2007;12(02):2-5

37 Bolduc C, Shapiro J. Hair care products: waving, straightening, conditioning, and coloring. Clin Dermatol 2001;19(04):431-436

38 van Zuuren EJ, Fedorowicz Z, Schoones J. Interventions for female pattern hair loss. Cochrane Database Syst Rev 2016;(05): CD007628

39 Shetty VH, Shetty NJ, Nair DG. Chemical hair relaxers have adverse effects a myth or reality. Int J Trichology 2013;5(01):26-28

40 Colenci AVP. Degradation of human hair caused by the use of contemporary straighteners and other chemical processes. 2017

41 Weathersby C, McMichael A. Brazilian keratin hair treatment: a review. J Cosmet Dermatol 2013;12(02):144-148

42 Towle KM, Grespin ME, Monnot AD. Personal use of hair dyes and risk of leukemia: a systematic literature review and meta-analysis. Cancer Med 2017;6(10):2471-2486

43 de Sá Dias TC, Baby AR, Kaneko TM, Robles Velasco MV. Relaxing/straightening of Afro-ethnic hair: historical overview. J Cosmet Dermatol 2007;6(01):2-5

44 Lucca JM, Joseph R, Hussain Al Kubaish Z, Mohammad Al-Maskeen S, Ali Alokaili Z. An observational study on adverse reactions of cosmetics: the need of practice the Cosmetovigilance system. Saudi Pharm J 2020;28(06):746-753

45 Quaresma MV, Martinez Velasco MA, Tosti A. Hair breakage in patients of African descent: role of dermoscopy.Page: 1. Skin Appendage Disord 2015;1(02):99-104 
46 Couto AC, Ferreira JD, Rosa AC, Pombo-de-Oliveira MS, Koifman SBrazilian Collaborative Study Group of Infant Acute Leukemia. Pregnancy, maternal exposure to hair dyes and hair straightening cosmetics, and early age leukemia. Chem Biol Interact 2013;205 (01):46-52

47 Gupta M, Mahajan VK, Mehta KS, Chauhan PS. Hair dye dermatitis and p-phenylenediamine contact sensitivity: a preliminary report. Indian Dermatol Online J 2015;6(04):241-246

48 Sharma VK, Sethuraman G, Garg T, Verma KK, Ramam M. Patch testing with the Indian standard series in New Delhi. Contact Dermat 2004;51(5-6):319-321

49 Uter W, Lessmann H, Geier J, Schnuch A. Contact allergy to hairdressing allergens in female hairdressers and clients-current data from the IVDK, 2003-2006. J Dtsch Dermatol Ges 2007;5(11): 993-1001

50 Scheman A, Cha C, Bhinder M. Alternative hair-dye products for persons allergic to para-phenylenediamine. Dermatitis 2011;22 (04):189-192

51 Gera R, Mokbel R, Igor I, Mokbel K. Does the use of hair dyes increase the risk of developing breast cancer? A meta-analysis and review of the literature. Anticancer Res 2018;38(02):707-716
52 Jafarzadeh L, Seifi N, Shahinfard N, et al. Antioxidant activity and teratogenicity evaluation of Lawsonia Inermis in BALB/c mice. J Clin Diagn Res 2015;9(05):FF01-FF04

53 Trakoli A. IARC Monographs on the Evaluation of Carcinogenic Risks to Humans. Volume 99: Some Aromatic Amines, Organic Dyes, and Related Exposures. International Agency for Research on Cancer. Oxford University Press2012

54 McCall EE, Olshan AF, Daniels JL. Maternal hair dye use and risk of neuroblastoma in offspring. Cancer Causes Control 2005;16(06): 743-748

55 McDonald JA, Tehranifar P, Flom JD, Terry MB, James-Todd T. Hair product use, age at menarche and mammographic breast density in multiethnic urban women. Environ Health 2018;17 (01): 1

56 Chabert M-C, Perrin J, Berbis J, Bretelle F, Adnot S, Courbiere B. Lack of information received by a French female cohort regarding prevention against exposure to reprotoxic agents during pregnancy. Eur J Obstet Gynecol Reprod Biol 2016;205:15-20

57 Parodi S, Merlo DF, Ranucci A, et al; SETIL Working Group. Risk of neuroblastoma, maternal characteristics and perinatal exposures: the SETIL study. Cancer Epidemiol 2014;38(06):686-694 